\title{
Probabilistic Risk Assessment of Inorganic Arsenic via Consumption of Herbs Collected in Thailand
}

\author{
Nuntawat Monboonpitak $\left(\mathbb{D},{ }^{1}\right.$ Suthep Ruangwises, ${ }^{2}$ \\ Sawanya Buranaphalin, ${ }^{1}$ and Nongluck Ruangwises $\mathbb{D I}^{1}$ \\ ${ }^{1}$ Department of Pharmaceutical Chemistry, Faculty of Pharmacy, Mahidol University, Sri Ayudhya Road, Ratchathewi, \\ Bangkok 10400, Thailand \\ ${ }^{2}$ Department of Veterinary Public Health, Faculty of Veterinary Science, Chulalongkorn University, Henri Dunant Road, \\ Bangkok 10330, Thailand
}

Correspondence should be addressed to Nongluck Ruangwises; nongluck.rua@mahidol.ac.th

Received 19 December 2017; Revised 18 June 2018; Accepted 23 June 2018; Published 15 July 2018

Academic Editor: Srinivas Nammi

Copyright (C) 2018 Nuntawat Monboonpitak et al. This is an open access article distributed under the Creative Commons Attribution License, which permits unrestricted use, distribution, and reproduction in any medium, provided the original work is properly cited.

\begin{abstract}
Total and inorganic arsenic contents in ten commonly consumed Thai herbs, namely, bird's eye chili, cayenne pepper, celery, garlic, holy basil, kitchen mint, lemongrass, pepper, shallot, and sweet basil, were determined using atomic absorption spectrometry coupled with a hydride generation system (HG-AAS). Total arsenic contents in fresh herbs and lyophilized herbs ranged from 3.39 to $119 \mathrm{ng} / \mathrm{g}$ wet weight (wet wt) and from 41.0 to $156 \mathrm{ng} / \mathrm{g}$ dry weight (dry wt), respectively. Inorganic arsenic contents in fresh herbs and lyophilized herbs ranged from 2.09 to $26.9 \mathrm{ng} / \mathrm{g}$ (wet wt) and from 23.5 to $55.5 \mathrm{ng} / \mathrm{g}$ (dry wt), respectively. Percentages of inorganic arsenic to total arsenic in herbs ranged from 22.7 to $62.0 \%$. High percentages of inorganic arsenic to total arsenic were found in celery, lemongrass and sweet basil. Total arsenic contents in the studied herbs were lower than the maximum limits of Thai and Chinese regulatory standards, set at 2,000 ng/g in foods (excluding aquatic animals and seafood) and $500 \mathrm{ng} / \mathrm{g}$ in fresh vegetables, respectively. Total and inorganic arsenic contents in the studied herbs were comparable to or lower than the levels found in other studies in the EU and China. Lifetime average daily dose (LADD) and cancer risk (CR) of inorganic arsenic exposure to commonly consumed herbs were evaluated using probabilistic risk assessment (PRA) by @RISK software version 6.0 of Palisade cooperation. All calculated LADD and CR values from all herbs did not exceed the acceptable levels. It can be concluded that there were very low cancer risks of inorganic arsenic exposure from the consumption of the studied herbs.
\end{abstract}

\section{Introduction}

Herbs have played an important role in traditional medicines and foods for centuries. At present, approximately 4 billion people (representing $80 \%$ of the world's population), especially in developing countries, use herbs or medicinal plants for therapeutic purposes or primary healthcare [1]. Traditional medicines produced from herbs or medicinal plants are used worldwide, with an increasing interest in developed or Western countries [2]. The increased application has raised concerns about the potential adverse effects of these herbs. In comparison to synthetic drugs, herbal drugs are generally considered to have a lower risk of side effects; however, they could possibly contain some toxic substances, such as heavy metals [3].
Arsenic (As) is a widespread environmental contaminant, resulting from both natural occurrences and human activities $[4,5]$. Volcanic eruptions and other natural processes are sources of arsenic in the environment. Human activities, including disposal of industrial chemicals, smelting of arsenic-bearing minerals, burning of fossil fuels, and the application of arsenic compounds in numerous products, also cause arsenic contamination $[4,5]$. Arsenic compounds are used in many manufacturing processes, including glass, electrical devices, pesticides, and pigments [5]. In addition, arsenic-containing pesticides that were widely used in the past have caused some agricultural areas to become contaminated with arsenic [6].

Acute and chronic toxicity of arsenic can involve the respiratory, cardiovascular, nervous and hematopoietic systems 
TABLE 1: Characteristics of the studied Thai herbs.

\begin{tabular}{lccc}
\hline Common name & Scientific name & Family & Edible part \\
\hline Bird's eye chili & Capsicum frutescens & Solanaceae & Fruits \\
Cayenne pepper & Capsicum annuum & Solanaceae & Fruits \\
Celery & Apium graveolens & Apiaceae & Leaves/Stems \\
Garlic & Allium sativum & Alliaceae & Clove \\
Holy basil & Ocimum sanctum & Lamiaceae & Leaves \\
Kitchen mint & Mentha cordifolia & Lamiaceae & Leaves \\
Lemongrass & Cymbopogon citratus & Gramineae & Stems \\
Pepper & Piper nigrum & Piperaceae & Fruits \\
Shallot & Allium cepa & Alliaceae & Clove \\
Sweet basil & Ocimum basilicum & Lamiaceae & Leaves \\
\hline
\end{tabular}

[4]. Inorganic arsenic compounds are more toxic than organic compounds, and the trivalent forms are more harmful than the pentavalent forms [5]. Inorganic arsenic compounds have been identified as human carcinogens, with evidence for an increased cancer risk of the urinary bladder, lung, and skin. Moreover, long-term exposure to inorganic arsenic has been reported to be associated with skin lesions, mental disorders, cardiovascular diseases, neurotoxicity, and diabetes [5]. The International Agency for Research on Cancer (IARC) has classified inorganic arsenic compounds as Group 1 carcinogens [7]. In 2010, the provisional tolerable weekly intake (PTWI) of arsenic at $15 \mu \mathrm{g} / \mathrm{kg}$ body weight (bw)/week was withdrawn. The Joint FAO/WHO Expert Committee on Food Additives (JECFA) has determined a benchmark dose lower confidence limit for a $0.5 \%$ increased incidence of lung cancer $\left(\mathrm{BMDL}_{0.5}\right)$ of $3.0 \mu \mathrm{g} / \mathrm{kg}$ bw/day (ranging from 2.0 to $7.0 \mu \mathrm{g} / \mathrm{kg}$ bw/day) [8]. European Food Safety Authority has identified a range of benchmark dose lower confidence limit (BMDL01) values of 0.3 and $8 \mu \mathrm{g} / \mathrm{kg}$ bw/day for cancers of the lung, skin, and bladder [9].

Foods are major sources of arsenic exposure in the general population. The dietary exposure to arsenic varies widely, depending on the food type, cultivation practices, environmental factors, and food processing methods [5]. The consumption of herbs can contribute to arsenic exposure because of arsenic contamination in the environment in which plants are cultivated (soil, irrigation water, and the atmosphere). Little information has been reported on the arsenic levels in Thai herbs. Thus, the aim of this study was to determine the total and inorganic arsenic contents in ten commonly consumed Thai herbs and to evaluate the health risks of inorganic arsenic exposure to commonly consumed herbs by the Thai population.

\section{Materials and Methods}

2.1. Chemicals. Nitric acid $\left(\mathrm{HNO}_{3}\right)$ and hydrochloric acid (HCl) were purchased from Merck (Darmstadt, Germany). Dimethylarsinic acid (DMA), hydrazine sulfate, hydrobromic acid, and other chemicals were purchased from SigmaAldrich (St. Louis, MO, USA). Rice flour (standard reference material [SRM] 1568a) was obtained from the National
Institute of Standards and Technology (Gaithersburg, MD, USA). All standard solutions, reagents, and samples were prepared using deionized water $(18 \mathrm{M} \Omega \mathrm{cm})$. To avoid arsenic residue contamination, all glassware was soaked in $10 \%(\mathrm{v} / \mathrm{v})$ $\mathrm{HNO}_{3}$ overnight and washed three times with deionized water before use.

2.2. Sample Collection. Ten herbs commonly consumed in Thailand were used in this study (Table 1). The samples were collected between February and May 2015 from 10 provinces (Chiang Mai, Chiang Rai, Khon Kaen, Lampang, Nakhon Pathom, Nakhon Ratchasima, Songkla, Suphan Buri, Trang, and Tak) of Thailand. Approximately $500 \mathrm{~g}$ of each sample was purchased from local markets and stored in clean plastic bags.

2.3. Sample Preparation. A total of 150 samples (15 samples for each herb) were determined for total and inorganic arsenic. The samples were first washed through tap water. Only the edible parts of each herb sample were used. The cleaned edible parts of samples were cut and air-dried, then frozen, and lyophilized. Each lyophilized sample was ground into fine powder using a mortar and pestle. Each powdered sample was passed through a fine mesh sieve and stored in an airtight container at $4^{\circ} \mathrm{C}$ until analysis.

2.4. Determination of Total Arsenic. Determination of total arsenic was performed using the method described by Muñoz et al. [12]. An aliquot of lyophilized sample (0.250 g) was mixed with $1 \mathrm{~mL}$ of ashing suspension $(20 \% \mathrm{w} / \mathrm{v}$ $\mathrm{Mg}\left(\mathrm{NO}_{3}\right)_{2} \cdot 6 \mathrm{H}_{2} \mathrm{O}$ and $2 \% \mathrm{w} / \mathrm{v} \mathrm{MgO}$ in water) and $5 \mathrm{~mL}$ of $50 \%(\mathrm{v} / \mathrm{v}) \mathrm{HNO}_{3}$. The mixture was evaporated on a hot plate to dryness and then mineralized at $450^{\circ} \mathrm{C}$ in a furnace. The resulting white ash was dissolved in $5 \mathrm{~mL}$ of $6 \mathrm{~N} \mathrm{HCl}$ and 5 $\mathrm{mL}$ of a reducing solution $(5 \% \mathrm{w} / \mathrm{v} \mathrm{KI}$ and $5 \% \mathrm{w} / \mathrm{v}$ ascorbic acid). The solution was left for $30 \mathrm{~min}$ and then $10 \mathrm{~mL}$ of $50 \% \mathrm{v} / \mathrm{v} \mathrm{HCl}$ was added to the solution. The solution was filtered through a Whatman No. 1 filter paper into a $25 \mathrm{~mL}$ volumetric flask and adjusted to volume with $50 \% \mathrm{v} / \mathrm{v} \mathrm{HCl}$. The resulting solution was used for determination of total arsenic. All samples were analyzed in duplicate.

2.5. Determination of Inorganic Arsenic. Inorganic arsenic was determined by the method described by Muñoz et al. 
[12]. An accurate weight $(0.500 \mathrm{~g})$ of lyophilized sample was placed in a $50 \mathrm{~mL}$ screw-capped centrifuge tube; 4.1 $\mathrm{mL}$ of water was added to the sample and mixed until completely moistened. In order to hydrolyze As(III) from the thiol groups of proteins, $18.4 \mathrm{~mL}$ of concentrated $\mathrm{HCl}$ was added to the moistened sample, shaken for $1 \mathrm{~h}$, and left overnight (12-15 h). Reducing agent ( $1 \mathrm{~mL}$ of $1.5 \%$ [w/v] hydrazine sulfate and $2 \mathrm{~mL}$ of hydrobromic acid) was added to the sample tube and vortexed for $2 \mathrm{~min}$. Chloroform (10 $\mathrm{mL}$ ) was added to the tube, which was then shaken and centrifuged at $1,000 \times g$ for 10 min using a bench-top centrifuge (model 5810; Eppendorf, Hamburg, Germany). The chloroform phase was aspirated into another centrifuge tube. The extraction process was repeated twice. The chloroform phase was then filtered through a syringe filter with a 25 $\mathrm{mm}$ polytetrafluoroethylene membrane, pore size $0.5 \mu \mathrm{m}$ (ChromTech, Apple Valley, MN, USA) into another $50-\mathrm{mL}$ tube. Inorganic arsenic in the chloroform phase was extracted with $10 \mathrm{~mL}$ of $1 \mathrm{~N} \mathrm{HCl}$ and centrifuged $(1,000 \times g$ for 10 $\min )$. The aqueous phase was aspirated into a beaker. The extraction process was repeated once more. The amount of inorganic arsenic in the combined aqueous acid phase was quantified as described in the determination of total arsenic, with the addition of $2.5 \mathrm{~mL}$ ashing suspension and $10 \mathrm{~mL}$ of $50 \%(\mathrm{v} / \mathrm{v}) \mathrm{HNO}_{3}$. All samples were analyzed in duplicate.

2.6. Instrumentation. An atomic absorption spectrophotometer (A Analyst 300; PerkinElmer, Waltham, MA, USA), equipped with an AS-90 autosampler, FIAS 400 flow injection system, arsenic hollow-cathode lamp, and hydride generation, was used for determination of total and inorganic arsenic contents in the final solutions. The operating conditions for HG-AAS were as described by Ruangwises et al. (2012) [13].

2.7. Determination of Limits of Quantitation. Limits of quantitation (LOQ) for total and inorganic arsenic were determined using the Q2B method of the USFDA [14]. For determination of the LOQ for total arsenic, lyophilized plant samples $(0.250 \mathrm{~g})$ were fortified with an arsenic mixture [As(III): $\operatorname{As}(\mathrm{V})$ 1:1 w/w] at concentrations of 250, 500, 1,000 and 2,500 ng/g; blank samples were not fortified with arsenic. Concentrations of total arsenic in fortified and blank samples were quantified as described in the determination of total arsenic. For determination of the LOQ for inorganic arsenic, lyophilized plant samples $(0.500 \mathrm{~g})$ were fortified with an arsenic mixture at concentrations of 50, 100, 500, and 1,000 ng/g; blank samples were not fortified with arsenic. Concentrations of inorganic arsenic in fortified and blank samples were quantified as described in the determination of inorganic arsenic.

2.8. Quality Assurance. The accuracy of total and inorganic arsenic determinations was assessed by determining the total and inorganic arsenic contents in the standard reference material (SRM) 1568a (rice flour). The accuracy was also tested using different concentrations of fortified samples, calculated as \% recovery. Intraday and interday precision were expressed as percentage of relative standard deviation (\% RSD).

2.9. Statistical Analysis. Statistical tests were conducted using the SPSS Statistics software program, version 18. One-way analysis of variance (ANOVA) with Tukey's post hoc test $(p<0.05)$ was used to examine the differences of total and inorganic arsenic contents in different kinds of herbs.

2.10. Intake Rate of Herbs. Individual intake rate of the studied herbs were obtained from the National Bureau of Agricultural Commodity and Food Standards with permission. The food consumption data of Thailand was conducted during 2003-2004. This consumption survey used food frequency questionnaires. The number of subjects included in the study was 18,746 people (9,316 male and 9,430 female; 2,363 of age $<3$ years and 16,383 of age $\geq 3$ years) from 17 provinces in Thailand including Bangkok. Intake rate data was used to calculate deterministic risk assessment and probabilistic risk assessment. Not all intake rate of the studied herbs has been reported; therefore the intake rate of some herbs was justified based on the available data.

2.11. Lifetime Average Daily Dose (LADD) and Cancer Risk $(C R)$. Lifetime average daily dose and cancer risk of inorganic arsenic exposure to commonly consumed herbs were evaluated using probabilistic risk assessment (PRA). PRA has been used in exposure assessment to estimate lifetime average daily exposure concentration by considering human variation and uncertainty [15]. PRA used @RISK software version 5.5 of Palisade cooperation. The probabilistic assessment was conducted by Monte Carlo simulation which estimates the possibility of the incidence. The appropriate distribution was selected to fit with the data. Each variable from the particular distribution of both arsenic concentration data and intake rate of herb were randomized using 10,000 iterations. Two types of exposure assessment were used including central tendency estimate (CTE) and reasonable maximum estimate (RME). The CTE model was calculated from average inorganic concentration and intake rate of the particular herb. The RME model was calculated from the 95th percentile of inorganic concentration and intake rate of the particular herb.

Lifetime average daily doses (LADD) from the consumption of the studied herbs were estimated by the following equation:

$$
\mathrm{LADD}=\frac{\mathrm{C} \times \mathrm{IR} \times \mathrm{ED}}{\mathrm{BW} \times \mathrm{LT}}
$$

where LADD is lifetime average daily doses ( $\mathrm{mg} / \mathrm{kg} / \mathrm{day}) ; \mathrm{C}$ is concentration of chemical ( $\mathrm{mg} / \mathrm{kg}$ food); IR is intake rate (kg/day); BW is body weight $(\mathrm{kg}) ; \mathrm{ED}$ is exposure duration (years); LT is lifetime (days).

Cancer risk characterization of inorganic arsenic exposure was estimated using the following equation:

$$
\mathrm{CR}=\mathrm{LADD} \times \mathrm{CSF}_{\mathrm{o}}
$$


TABLE 2: Accuracy (\% recovery) and precision (\% RSD) in determination of total and inorganic arsenic in herbs.

\begin{tabular}{|c|c|c|c|c|c|c|}
\hline \multirow[b]{2}{*}{$\begin{array}{l}\text { Arsenic spiked } \\
(\mathrm{ng} / \mathrm{g})\end{array}$} & \multicolumn{3}{|c|}{ Intraday $(n=6)$} & \multicolumn{3}{|c|}{ Interday $(n=6)$} \\
\hline & $\begin{array}{c}\text { Found } \\
(\mathrm{ng} / \mathrm{g}) \\
(\text { mean } \pm \mathrm{SD})\end{array}$ & $\begin{array}{l}\text { RSD } \\
(\%)\end{array}$ & Recovery (\%) & $\begin{array}{c}\text { Found } \\
(\mathrm{ng} / \mathrm{g}) \\
(\text { mean } \pm \mathrm{SD})\end{array}$ & $\begin{array}{c}\text { RSD } \\
(\%)\end{array}$ & Recovery (\%) \\
\hline \multicolumn{7}{|l|}{ Total arsenic } \\
\hline 250 & $244 \pm 8.53$ & 3.49 & 97.7 & $237 \pm 6.68$ & 2.82 & 94.9 \\
\hline 500 & $473 \pm 13.6$ & 2.88 & 94.6 & $478 \pm 21.2$ & 4.43 & 95.6 \\
\hline 1000 & $945 \pm 32.6$ & 3.45 & 94.5 & $972 \pm 48.5$ & 5.00 & 97.2 \\
\hline 2500 & $2,370 \pm 41.4$ & 1.75 & 94.7 & $2.38 \times 10^{3} \pm 40.5$ & 1.70 & 95.3 \\
\hline \multicolumn{7}{|l|}{$\begin{array}{l}\text { Inorganic } \\
\text { arsenic }\end{array}$} \\
\hline 50 & $47.4 \pm 2.54$ & 5.37 & 94.8 & $47.7 \pm 2.57$ & 5.38 & 95.3 \\
\hline 100 & $98.1 \pm 4.81$ & 4.91 & 98.1 & $97.9 \pm 3.36$ & 3.43 & 97.9 \\
\hline 500 & $469.8 \pm 25.2$ & 5.35 & 94.0 & $473 \pm 21.9$ & 4.63 & 94.6 \\
\hline 1000 & $943.8 \pm 13.4$ & 1.42 & 94.4 & $941 \pm 11.1$ & 1.18 & 94.1 \\
\hline
\end{tabular}

TABLE 3: Moisture contents and limits of quantification (LOQs) of total and inorganic arsenic of individual herbs.

\begin{tabular}{|c|c|c|c|}
\hline & Average Moisture Content (\%) & LOQ (total arsenic wet wt) & LOQ (inorganic arsenic, wet wt) \\
\hline $\begin{array}{l}\text { Bird's eye chili } \\
\text { (Capsicum } \\
\text { frutescens) }\end{array}$ & 64.2 & 6.80 & 5.37 \\
\hline $\begin{array}{l}\text { Cayenne pepper } \\
\text { (Capsicum } \\
\text { annuum) }\end{array}$ & 73.7 & 5.00 & 3.95 \\
\hline $\begin{array}{l}\text { Celery } \\
\text { (Apium graveolens) }\end{array}$ & 91.6 & 1.60 & 1.26 \\
\hline $\begin{array}{l}\text { Garlic } \\
\text { (Allium sativum) }\end{array}$ & 86.5 & 2.57 & 2.03 \\
\hline $\begin{array}{l}\text { Holy basil } \\
\text { (Ocimum sanctum) }\end{array}$ & 79.5 & 3.90 & 3.08 \\
\hline $\begin{array}{l}\text { Kitchen mint } \\
\text { (Mentha cordifolia) }\end{array}$ & 87.0 & 2.47 & 1.95 \\
\hline $\begin{array}{l}\text { Lemongrass } \\
\text { (Cymbopogon } \\
\text { citratus) }\end{array}$ & 68.2 & 6.04 & 4.77 \\
\hline $\begin{array}{l}\text { Pepper } \\
\text { (Piper nigrum) }\end{array}$ & 9.53 & 17.2 & 13.6 \\
\hline $\begin{array}{l}\text { Shallot } \\
\text { (Allium cepa) }\end{array}$ & 91.9 & 1.54 & 1.22 \\
\hline $\begin{array}{l}\text { Sweet basil } \\
\text { (Ocimum } \\
\text { basilicum) }\end{array}$ & 81.6 & 3.50 & 2.76 \\
\hline
\end{tabular}

where CR is cancer risk, a unitless probability; $\mathrm{CSF}_{\mathrm{o}}$ is oral cancer slope factor for inorganic arsenic $=1.5$ per $\mathrm{mg} / \mathrm{kg}$ bw/day.

\section{Results}

The accuracy of this analytical method was assessed by determination of the total arsenic and inorganic arsenic contents in SRM 1568a rice flour. Concentrations of total arsenic and inorganic arsenic found in rice flour were $283 \pm$ $34 \mathrm{ng} / \mathrm{g}(n=10$, reference value of $290 \pm 30 \mathrm{ng} / \mathrm{g})$ and $102 \pm 4$ $\mathrm{ng} / \mathrm{g}(n=10)$, respectively [13]. The concentration of inorganic arsenic was in agreement with previous reports of $111 \pm 6 \mathrm{ng} / \mathrm{g}$ [16] and $111 \pm 3 \mathrm{ng} / \mathrm{g}$ [17] using the same method of analysis.

The accuracy using different concentrations of fortified samples, calculated as \% recovery, was also tested. The intraday and interday precision was expressed as percentage of relative standard deviation (\% RSD). The \% recovery and \% $\mathrm{RSD}$ of the total and inorganic arsenic determinations in herb samples fortified with arsenic mixture at four concentrations were in an acceptable range (Table 2). The average recoveries across the four concentrations of fortified arsenic mixtures 
TABLE 4: Total and inorganic arsenic contents and percentage of inorganic arsenic in Thai herbs, expressed as mean \pm standard deviation (minimum-maximum).

\begin{tabular}{|c|c|c|c|c|c|}
\hline \multirow{2}{*}{ Herb } & \multicolumn{2}{|c|}{ Total arsenic (ng/g) } & \multicolumn{2}{|c|}{ Inorganic arsenic (ng/g) } & \multirow{2}{*}{$\begin{array}{l}\% \text { Inorganic } \\
\text { arsenic }^{*}\end{array}$} \\
\hline & Wet weight & Dry weight & Wet weight & Dry weight & \\
\hline $\begin{array}{l}\text { Bird's eye chili } \\
\text { (Capsicum frutescens) }\end{array}$ & $\begin{array}{r}40.5 \pm 14.9^{\mathrm{b}} \\
(28.0-79.2)\end{array}$ & $\begin{array}{l}113 \pm 39.7^{\mathrm{b}} \\
(78.3-219)\end{array}$ & $\begin{array}{r}14.4 \pm 3.72^{\mathrm{c}} \\
(9.31-23.5)\end{array}$ & $\begin{array}{c}40.2 \pm 10.2^{\mathrm{bc}} \\
(24.9-63.8)\end{array}$ & $\begin{array}{c}36.6 \pm 5.95^{\mathrm{ce}} \\
(27.2-46.1)\end{array}$ \\
\hline $\begin{array}{l}\text { Cayenne pepper } \\
\text { (Capsicum annuum) }\end{array}$ & $\begin{array}{r}16.4 \pm 2.21^{\mathrm{ef}} \\
(13.3-19.9)\end{array}$ & $\begin{array}{c}62.7 \pm 8.26^{\mathrm{de}} \\
(47.2-81.9)\end{array}$ & $\begin{array}{r}7.83 \pm 1.74^{\mathrm{d}} \\
(6.15-13.3)\end{array}$ & $\begin{array}{l}29.9 \pm 7.31^{\mathrm{ce}} \\
(23.8-54.6)\end{array}$ & $\begin{array}{c}47.7 \pm 7.39^{\mathrm{ac}} \\
(35.7-66.7)\end{array}$ \\
\hline $\begin{array}{l}\text { Celery } \\
\text { (Apium graveolens) }\end{array}$ & $\begin{array}{c}3.39 \pm 0.940^{\mathrm{g}} \\
(1.96-5.81)\end{array}$ & $\begin{array}{l}41.0 \pm 11.8^{\mathrm{e}} \\
(30.4-77.5)\end{array}$ & $\begin{array}{c}2.09 \pm 0.566^{\mathrm{e}} \\
(1.28-3.37)\end{array}$ & $\begin{array}{c}25.3 \pm 6.81^{\mathrm{de}} \\
(17.2-39.6)\end{array}$ & $\begin{array}{l}62.1 \pm 7.93^{\mathrm{a}} \\
(48.8-75.4)\end{array}$ \\
\hline $\begin{array}{l}\text { Garlic } \\
\text { (Allium sativum) }\end{array}$ & $\begin{array}{c}8.01 \pm 2.06^{\mathrm{fg}} \\
(6.49-13.1)\end{array}$ & $\begin{array}{c}59.9 \pm 12.8^{\mathrm{de}} \\
(42.6-79.8)\end{array}$ & $\begin{array}{l}3.15 \pm 1.00^{\mathrm{e}} \\
(/ 2.05-5.54)\end{array}$ & $\begin{array}{r}23.5 \pm 6.60^{\mathrm{e}} \\
(15.5-36.9)\end{array}$ & $\begin{array}{c}39.3 \pm 6.46^{\mathrm{bc}} \\
(30.7-48.8)\end{array}$ \\
\hline $\begin{array}{l}\text { Holy basil } \\
\text { (Ocimum sanctum) }\end{array}$ & $\begin{array}{c}26.6 \pm 7.13^{\mathrm{cd}} \\
(13.2-44.9)\end{array}$ & $\begin{array}{c}128 \pm 22.8^{\mathrm{ab}} \\
(73.4-177)\end{array}$ & $\begin{array}{l}9.64 \pm 2.61^{\mathrm{d}} \\
(5.95-14.6)\end{array}$ & $\begin{array}{c}46.8 \pm 9.97^{\mathrm{ab}} \\
(31.4-66.1)\end{array}$ & $\begin{array}{l}37.0 \pm 7.19^{\mathrm{ce}} \\
(24.8-47.0)\end{array}$ \\
\hline $\begin{array}{l}\text { Kitchen mint } \\
\text { (Mentha cordifolia) }\end{array}$ & $\begin{array}{c}10.5 \pm 3.00^{\mathrm{eg}} \\
(6.46-16.0)\end{array}$ & $\begin{array}{c}80.6 \pm 16.1^{\mathrm{cd}} \\
(49.0-96.8)\end{array}$ & $\begin{array}{r}4.00 \pm 1.08^{\mathrm{e}} \\
(1.95-5.77)\end{array}$ & $\begin{array}{c}31.0 \pm 7.20^{\mathrm{ce}} \\
(16.6-42.8)\end{array}$ & $\begin{array}{c}38.6 \pm 5.65^{\mathrm{bcd}} \\
(30.2-46.7)\end{array}$ \\
\hline $\begin{array}{l}\text { Lemongrass } \\
\text { (Cymbopogon citratus) }\end{array}$ & $\begin{array}{c}32.0 \pm 5.38^{b c} \\
(23.4-43.3)\end{array}$ & $\begin{array}{c}100 \pm 16.1^{\mathrm{bc}} \\
(73.4-127)\end{array}$ & $\begin{array}{l}17.7 \pm 2.81^{\mathrm{b}} \\
(14.2-25.2)\end{array}$ & $\begin{array}{l}55.5 \pm 8.12^{\mathrm{a}} \\
(44.5-73.8)\end{array}$ & $\begin{array}{l}56.0 \pm 8.43^{\mathrm{a}} \\
(44.4-68.3)\end{array}$ \\
\hline $\begin{array}{l}\text { Pepper } \\
\text { (Piper nigrum) }\end{array}$ & $\begin{array}{c}119 \pm 19.0^{\mathrm{a}} \\
(84.2-149.6)\end{array}$ & $\begin{array}{r}132 \pm 21.0^{\mathrm{ab}} \\
(92.4-166)\end{array}$ & $\begin{array}{r}26.9 \pm 5.39^{\mathrm{a}} \\
(13.9-33.5)\end{array}$ & $\begin{array}{c}29.7 \pm 6.03^{\mathrm{ce}} \\
(15.3-37.3)\end{array}$ & $\begin{array}{r}22.7 \pm 4.30^{\mathrm{e}} \\
(15.4-31.1)\end{array}$ \\
\hline $\begin{array}{l}\text { Shallot } \\
\text { (Allium cepa) }\end{array}$ & $\begin{array}{c}12.6 \pm 5.05^{\mathrm{eg}} \\
(5.13-26.3)\end{array}$ & $\begin{array}{r}156 \pm 52.2^{\mathrm{a}} \\
(87.0-263)\end{array}$ & $\begin{array}{l}2.87 \pm 1.07^{\mathrm{e}} \\
(1.34-4.86)\end{array}$ & $\begin{array}{c}34.6 \pm 7.42^{\mathrm{cd}} \\
(22.7-50.1)\end{array}$ & $\begin{array}{c}24.1 \pm 7.15^{\mathrm{de}} \\
(10.5-32.5)\end{array}$ \\
\hline $\begin{array}{l}\text { Sweet basil } \\
\text { (Ocimum basilicum) }\end{array}$ & $\begin{array}{c}18.6 \pm 6.09^{\mathrm{de}} \\
(10.0-35.4)\end{array}$ & $\begin{array}{r}102 \pm 37.7^{\mathrm{bc}} \\
(59.2-207)\end{array}$ & $\begin{array}{r}8.56 \pm 3.40^{\mathrm{d}} \\
(6.33-20.3)\end{array}$ & $\begin{array}{c}46.3 \pm 16.6^{\mathrm{ab}} \\
(30.8-104)\end{array}$ & $\begin{array}{c}52.2 \pm 33.7^{\mathrm{ab}} \\
(22.3-159)\end{array}$ \\
\hline
\end{tabular}

A total of 150 samples (15 samples for each herb) were determined for total arsenic and inorganic arsenic.

$\mathrm{a}, \mathrm{b}, \mathrm{c}, \mathrm{d}, \mathrm{e}, \mathrm{f}, \mathrm{g}=$ mean values with different superscripts in the same column are significantly different $(p<0.05)$.

$* \%$ inorganic arsenic $=($ concentration of inorganic arsenic $\times 100) /$ concentration of total arsenic.

were $95.6 \%$ and $95.4 \%$ for total and inorganic arsenic, respectively. The precision of the method was calculated with the equation $\% \mathrm{RSD}=100 \mathrm{SD} / \overline{\mathrm{x}}$, where $\mathrm{SD}$ is the standard deviation and $\overline{\mathrm{x}}$ is the mean arsenic concentration recovered from the arsenic-fortified samples. The \% RSD ranged from 1.70 to $5.00 \%$ for total arsenic and from 1.18 to $5.38 \%$ for inorganic arsenic. The calculation for LOQ was based on the standard deviation of $y$-intercepts from linear regression analysis (ó) and the mean of the slope (S), using the equation $\mathrm{LOQ}=10 \mathrm{o} / \mathrm{S}$. The LOQs for total and inorganic arsenic in herb samples were 19 and $15 \mathrm{ng} / \mathrm{g}$ dry weight, respectively. Since different moisture contents were found in each herb, LOQs for total and inorganic arsenic (wet wt) were calculated for individual herbs (Table 3).

Total and inorganic arsenic contents and the percentage of inorganic arsenic to total arsenic in ten herbs collected in Thailand are shown in Table 4. There was a wide variation of total arsenic content in the studied herbs, ranging from 3.39 to $119 \mathrm{ng} / \mathrm{g}$ wet weight (wt), with a significant difference $(p<0.05)$. The highest level of total arsenic was found in pepper (119 ng/g wet wt). Total arsenic content in lyophilized herbs ranged from 41.0 to $156 \mathrm{ng} / \mathrm{g}$ dry wt, with a significant difference $(p<0.05)$. The highest contents of total arsenic (dry wt) were found in shallot $(156 \mathrm{ng} / \mathrm{g})$, pepper $(132 \mathrm{ng} / \mathrm{g})$ and holy basil (128 ng/g).

Inorganic arsenic content in herbs ranged from 2.09 to $26.9 \mathrm{ng} / \mathrm{g}$ wet $\mathrm{wt}$, with a significant difference $(p<0.05)$. Pepper also contained the highest level of inorganic arsenic (26.9 ng/g wet wt). Inorganic arsenic content in lyophilized
TABLE 5: Intake rates of the studied herbs.

\begin{tabular}{lcc}
\hline \multirow{2}{*}{ Herb } & \multicolumn{2}{c}{ Intake rate* } \\
& Average intake (g/day) & 95 Percentile intake (g/day) \\
\hline Bird's eye chili & 1.49 & 9.60 \\
Cayenne pepper & 1.49 & 9.60 \\
Celery & 0.94 & 3.75 \\
Garlic & 3.36 & 10.0 \\
Holy basil & 0.18 & 1.00 \\
Kitchen mint & 0.94 & 3.75 \\
Lemongrass & 2.87 & 13.4 \\
Pepper & 0.13 & 0.50 \\
Shallot & 2.68 & 9.00 \\
Sweet basil & 0.18 & 1.00
\end{tabular}

*Probability distribution of intake rate was conducted by Monte Carlo simulation using @RISK software version 5.5 of Palisade cooperation.

herbs ranged from 23.5 to $55.5 \mathrm{ng} / \mathrm{g}$ dry wt, with a significant difference $(p<0.05)$. The highest contents of inorganic arsenic (dry wt) were found in lemongrass $(55.5 \mathrm{ng} / \mathrm{g}$ ), holy basil $(46.8 \mathrm{ng} / \mathrm{g})$ and sweet basil $(46.3 \mathrm{ng} / \mathrm{g})$. Percentages of inorganic arsenic to total arsenic in herbs ranged from 22.7 to $62.0 \%$, with the highest percentages occurring in celery (62.0\%), lemongrass (56.0\%), sweet basil (52.2\%) and cayenne pepper $(47.7 \%)$.

The intake rates of the studied herbs are presented in Table 5. For the average intake level, the highest intake was found in garlic ( $3.36 \mathrm{~g} /$ day) followed by lemongrass ( 2.87 
TABLE 6: LADD and CR of inorganic arsenic exposure from the studied herbs using probabilistic risk assessment.

\begin{tabular}{lcccc}
\hline \multirow{2}{*}{ Herb } & \multicolumn{2}{c}{ LADD $(\mathrm{mg} / \mathrm{kg}$ bw/day) } & \multicolumn{2}{c}{ CR } \\
\hline Bird's eye chili & CTE & RME & $6.02 \times 10^{-7}$ & \\
Cayenne pepper & $4.01 \times 10^{-7}$ & $12.7 \times 10^{-7}$ & $3.20 \times 10^{-7}$ & \\
Celery & $2.13 \times 10^{-7}$ & $6.59 \times 10^{-7}$ & $0.56 \times 10^{-7}$ & $9.89 \times 10^{-7}$ \\
Garlic & $0.37 \times 10^{-7}$ & $1.20 \times 10^{-7}$ & $4.17 \times 10^{-7}$ & $1.79 \times 10^{-7}$ \\
Holy basil & $2.78 \times 10^{-7}$ & $9.26 \times 10^{-7}$ & $0.48 \times 10^{-7}$ & $13.9 \times 10^{-7}$ \\
Kitchen mint & $0.32 \times 10^{-7}$ & $1.00 \times 10^{-7}$ & $1.06 \times 10^{-7}$ & $1.50 \times 10^{-7}$ \\
Lemongrass & $0.71 \times 10^{-7}$ & $2.30 \times 10^{-7}$ & $14.1 \times 10^{-7}$ & $3.45 \times 10^{-7}$ \\
Pepper & $9.40 \times 10^{-7}$ & $29.0 \times 10^{-7}$ & $0.920 \times 10^{-7}$ & $43.6 \times 10^{-7}$ \\
Shallot & $0.620 \times 10^{-7}$ & $1.94 \times 10^{-7}$ & $2.19 \times 10^{-7}$ & $2.91 \times 10^{-7}$ \\
Sweet basil & $1.46 \times 10^{-7}$ & $4.82 \times 10^{-7}$ & $0.400 \times 10^{-7}$ & $7.22 \times 10^{-7}$ \\
\hline
\end{tabular}

g/day) and shallot (2.68 g/day), while, at the 95 percentile intake level, the highest intake was found in lemongrass (13.4 $\mathrm{g} /$ day), garlic (10.0 g/day), and bird's eye chili and cayenne pepper ( $9.6 \mathrm{~g} /$ day).

Table 6 shows lifetime average daily dose (LADD) and cancer risk (CR) of inorganic arsenic exposure from the studied herbs consumption using PRA with CTE and RME models. Cancer risk is the theoretical maximum number of cancer cases that are expected to develop due to the exposure to a carcinogen. The acceptable lifetime cancer risk for inorganic arsenic is $10^{-5}$ (1 in 100,000). The highest LADD and CR of inorganic arsenic exposure were found from the consumption of lemongrass. All LADD values calculated from both CTE and RME models of inorganic arsenic exposure from all herbs were much lower than the benchmark dose level $\left(\mathrm{BMDL}_{0.5}\right)$ for lung cancer established by JECFA at $3 \times 10^{-3} \mathrm{mg} / \mathrm{kg} /$ day $\left(2-7 \times 10^{-3} \mathrm{mg} / \mathrm{kg} /\right.$ day based on the range of estimated total dietary exposure). Cancer risk values calculated from the RME model of inorganic arsenic exposure from all herbs do not exceed the acceptable cancer risk at $10^{-5}$. The results indicated that there were very low cancer risks of inorganic arsenic exposure from consumption of the studied herbs.

\section{Discussion}

Established maximum levels for total and inorganic arsenic in herbs are scarce. Thailand has set a maximum level of 2,000 $\mathrm{ng} / \mathrm{g}$ total arsenic in foods (excluding aquatic animals and seafood) [18], while China has established a maximum limit of $500 \mathrm{ng} / \mathrm{g}$ total arsenic in fresh vegetables [19]. Total arsenic contents in the studied herbs were lower than the Thai and Chinese regulatory standards. Considering rice which is a staple food contributing to high intake of inorganic arsenic exposure [8], maximum levels for inorganic arsenic contents in husked rice and polished rice were determined by Codex at the levels of 350 and $200 \mathrm{ng} / \mathrm{g}$, respectively [20], while European Union (EU) has established maximum levels of inorganic arsenic contents in husked rice and polished rice of 250 and $200 \mathrm{ng} / \mathrm{g}$, respectively [21]. Maximum level of inorganic arsenic in rice of $200 \mathrm{ng} / \mathrm{g}$ has also been set by the Chinese government [19]. Inorganic arsenic contents in all herbs in the present study were also below the maximum levels of inorganic arsenic in rice established by Codex, EU and China.

Studies on the total and inorganic arsenic contents in herbs have been limited. As shown in Table 7, total and inorganic arsenic contents in Thai herbs from the present study were comparable to or lower than the levels found in other studies $[10,11]$. The total and inorganic arsenic contents in dietary supplements (based on herbs, other botanicals and algae) sold in Denmark were reported in the range of 580-5000 and 30-3200 ng/g, respectively [22] which were much higher than the levels of total and inorganic arsenic found in the present study. It could be due the fact that to the diet supplements were prepared from the extract or dry powder of plant materials. In addition, the major herbal or plant ingredients of the dietary supplements studied [22] were different from the herbs used in our study.

Cancer risks of inorganic arsenic from herb consumption in this study were lower than the previous studies. A few studies reported cancer risk of inorganic arsenic from herb or vegetable consumption. Rehman et al. (2016) reported CR of inorganic arsenic from different vegetable consumption in Pakistani population ranged from $4.67 \times 10^{-6}$ (winter melon) to $98.8 \times 10^{-6}$ (coriander) [23]. Uddh-Söderberg et al. (2015) reported the CR at $2 \times 10^{-4}$ of arsenic exposure via consumption of homegrown vegetables near contaminated glassworks sites in Sweden [24].

This study shows that there were very low cancer risks of inorganic arsenic exposure from consumption of the studied herbs. Further research work may integrate the inorganic arsenic exposure from herb consumption in this study with other dietary sources to investigate the cancer risk from dietary exposure to inorganic arsenic in Thai population.

\section{Conclusions}

The present findings show that arsenic contents in the studied herbs collected in Thailand were lower than the available maximum limits for arsenic that have been established for various commodities. It can be concluded that, in terms of arsenic levels, these Thai herbs are safe for consumption and exportation. However, regular monitoring of inorganic 
TABLE 7: Total and inorganic arsenic contents in some herbs from the present study compared to the available literature data.

\begin{tabular}{|c|c|c|c|c|}
\hline Herb & Location & Total arsenic (ng/g wet wt) & $\begin{array}{c}\text { Inorganic } \\
\text { arsenic } \\
\text { (ng/g wet wt) }\end{array}$ & Reference \\
\hline \multirow{2}{*}{$\begin{array}{l}\text { Bird's eye chili } \\
\text { (Capsicum frutescens) }\end{array}$} & EU & - & 9.00 & [10] \\
\hline & Thailand & 40.5 & 14.4 & Present study \\
\hline \multirow{2}{*}{$\begin{array}{l}\text { Cayenne pepper } \\
\text { (Capsicum annuum) }\end{array}$} & $\mathrm{EU}$ & - & 12.0 & [10] \\
\hline & Thailand & 16.4 & 7.80 & Present study \\
\hline \multirow{3}{*}{$\begin{array}{l}\text { Celery } \\
\text { (Apium graveolens) }\end{array}$} & $\mathrm{EU}$ & - & 10.9 & [10] \\
\hline & China & 72.1 & - & {$[11]$} \\
\hline & Thailand & 3.40 & 2.90 & Present study \\
\hline \multirow{2}{*}{$\begin{array}{l}\text { Garlic } \\
\text { (Allium sativum) }\end{array}$} & China & 60.2 & - & {$[11]$} \\
\hline & Thailand & 8.00 & 3.20 & Present study \\
\hline \multirow{2}{*}{$\begin{array}{l}\text { Pepper } \\
\text { (Piper nigrum) }\end{array}$} & $\mathrm{EU}$ & - & 53.6 & {$[10]$} \\
\hline & Thailand & 119 & 26.9 & Present study \\
\hline \multirow{2}{*}{$\begin{array}{l}\text { Sweet basil } \\
\text { (Ocimum basilicum) }\end{array}$} & $\mathrm{EU}$ & - & 31.6 & {$[10]$} \\
\hline & Thailand & 18.6 & 8.60 & Present study \\
\hline
\end{tabular}

arsenic contamination in plants and risk assessment of inorganic arsenic exposure are suggested to ensure food safety.

\section{Conflicts of Interest}

The authors declare that they have no conflicts of interest.

\section{Acknowledgments}

The authors thank Mr. Janewit Wongsanoon for his technical assistance on determination of inorganic arsenic and $\mathrm{Mr}$. Christopher Salisbury, Chiang Mai University, Thailand, for editing this manuscript and acknowledge the National Bureau of Agricultural Commodity and Food Standards, Ministry of Agriculture and Cooperatives, Thailand, for the permission on using the food consumption data.

\section{References}

[1] M. Ekor, "The growing use of herbal medicines: Issues relating to adverse reactions and challenges in monitoring safety," Frontiers in Neurology, vol. 4, article 177, 2014.

[2] S. A. Jordan, D. G. Cunningham, and R. J. Marles, "Assessment of herbal medicinal products: challenges, and opportunities to increase the knowledge base for safety assessment," Toxicology and Applied Pharmacology, vol. 243, no. 2, pp. 198-216, 2010.

[3] P. A. G. M. De Smet, "Health risks of herbal remedies: An update," Clinical Pharmacology \& Therapeutics, vol. 76, no. 1, pp. $1-17,2004$.

[4] M. Bissen and F. H. Frimmel, "Arsenic-a review. Part I: occurrence, toxicity, speciation, mobility," Acta Hydrochimica et Hydrobiologica, vol. 31, no. 1, pp. 9-18, 2003.

[5] WHO, "Arsenic and arsenic compounds (Environmental health criteria 227)," in International Programme on Chemical Safety, World Health Organization (WHO), Geneva, Switzerland, 2nd edition, 2001.
[6] O. M. Ni Dhubhghaill and P. J. Sadler, "The structure and reactivity of arsenic compounds: Biological activity and drug design," in Bioinorganic Chemistry, vol. 78 of Structure and Bonding, pp. 129-190, Springer, Berlin, Germany, 1991.

[7] IARC, Arsenic And Arsenic Compounds, International Agency for Research on Cancer (IARC), 2012, http://monographs.iarc .fr/ENG/Monographs/vol100C/mono100C-6.pdf.

[8] World Health Organization (WHO), "Evaluation of certain contaminants in food (seventy-second report of the joint fao/who expert committee on food additives)," Tech. Rep., World Health Organization (WHO), Geneva, Switzerland, 2011, http://apps.who.int/iris/bitstream/10665/44514/1/WHO_TRS_ 959_eng.pdf.

[9] EFSA, "Evaluation of certain contaminants in food (seventysecond report of the joint fao/who expert committee on food additives)," Tech. Rep., European Food Safety Authority (EFSA), Parma, Italy, 2009.

[10] EFSA, "Dietary exposure to inorganic arsenic in the European population," EFSA Journal, vol. 12, no. 3, 2014.

[11] R.-Q. Huang, S.-F. Gao, W.-L. Wang, S. Staunton, and G. Wang, "Soil arsenic availability and the transfer of soil arsenic to crops in suburban areas in Fujian Province, southeast China," Science of the Total Environment, vol. 368, no. 2-3, pp. 531-541, 2006.

[12] O. Muñoz, D. Vélez, and R. Montoro, "Optimization of the solubilization, extraction and determination of inorganic arsenic $[\mathrm{As}(\mathrm{III})+\mathrm{As}(\mathrm{v})]$ in seafood products by acid digestion, solvent extraction and hydride generation atomic absorption spectrometry," Analyst, vol. 124, no. 4, pp. 601-607, 1999.

[13] S. Ruangwises, P. Saipan, B. Tengjaroenkul, and N. Ruangwises, "Total and inorganic arsenic in rice and rice bran purchased in Thailand," Journal of Food Protection, vol. 75, no. 4, pp. 771-774, 2012.

[14] USFDA, "Guidance for industry - Q2B validation of analytical procedures: methodology," Tech. Rep., Center for Drug Evaluation and Research, Rockville, Md, USA, 1996.

[15] USEPA, "Risk assessment forum white paper: probabilistic risk assessment methods and case studies," Tech. Rep., Office of 
the science advisor risk assessment forum, Washington, Wash, USA, 2014.

[16] O. Muñoz, O. P. Diaz, I. Leyton et al., "Vegetables collected in the cultivated Andean area of Northern Chile: Total and inorganic arsenic contents in raw vegetables," Journal of Agricultural and Food Chemistry, vol. 50, no. 3, pp. 642-647, 2002.

[17] S. Torres-Escribano, M. Leal, D. Vélez, and R. Montoro, “Total and inorganic arsenic concentrations in rice sold in Spain, effect of cooking, and risk assessments," Environmental Science \& Technology, vol. 42, no. 10, pp. 3867-3872, 2008.

[18] Thailand Ministry of Public Health, Notification of the Ministry of Public Health (No. 273) B.E. 2546, Food residues, vol. 120, , Special Issue 77D, The Government Gazette, Bangkok, Thailand, 2nd edition, 2003.

[19] J. Clever and M. Jie, "China's maximum levels for contaminants in foods," USDA Foreign Agricultural Service GAIN Report CH14058, USDA Foreign Agricultural Service, Global Agricultural Information Network, 2014.

[20] CODEX STAN, "General standard for contaminants and toxins in foods and feed," Tech. Rep. CODEX STAN 193-1995, Codex Alimentarius Commission, World Health Organization, Geneva, Switzerland, 1995.

[21] European Commission, "Commission Regulation (EU) 2015/ 1006 of 25 June 2015 amending Regulation (EC) No 1881/ 2006 as regards maximum levels of inorganic arsenic in foodstuffs," Official Journal of the European Union, no. L161/14, 2015, https://eur-lex.europa.eu/legal-content/EN/TXT/PDF/?uri= CELEX:32015R1006\&amp;from=EN.

[22] R. V. Hedegaard, I. Rokkjær, and J. J. Sloth, “Total and inorganic arsenic in dietary supplements based on herbs, other botanicals and algae-a possible contributor to inorganic arsenic exposure," Analytical and Bioanalytical Chemistry, vol. 405, no. 13, pp. 4429-4435, 2013.

[23] Z. U. Rehman, S. Khan, K. Qin, M. L. Brusseau, M. T. Shah, and I. Din, "Quantification of inorganic arsenic exposure and cancer risk via consumption of vegetables in southern selected districts of Pakistan," Science of the Total Environment, vol. 550, pp. 321329, 2016.

[24] T. E. Uddh-Söderberg, S. J. Gunnarsson, K. J. Hogmalm, M. I. B. G. Lindegård, and A. L. M. Augustsson, "An assessment of health risks associated with arsenic exposure via consumption of homegrown vegetables near contaminated glassworks sites," Science of the Total Environment, vol. 536, pp. 189-197, 2015. 


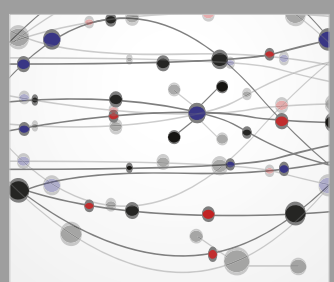

The Scientific World Journal
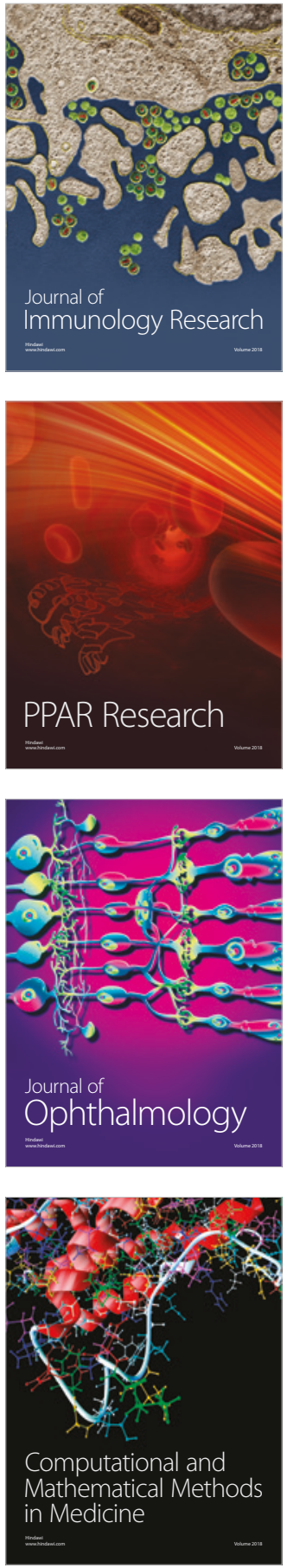



Gastroenterology Research and Practice

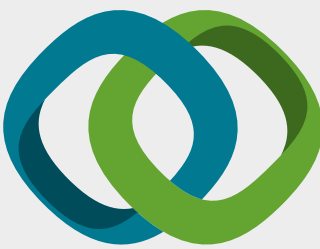

\section{Hindawi}

Submit your manuscripts at

www.hindawi.com


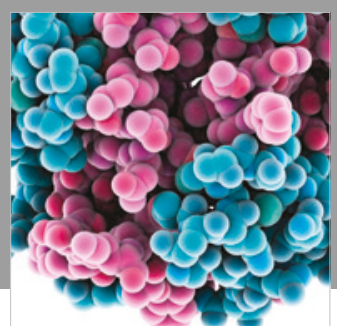

ournal of

Diabetes Research

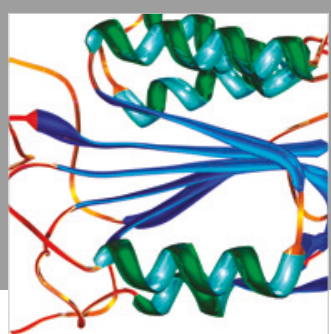

Disease Markers
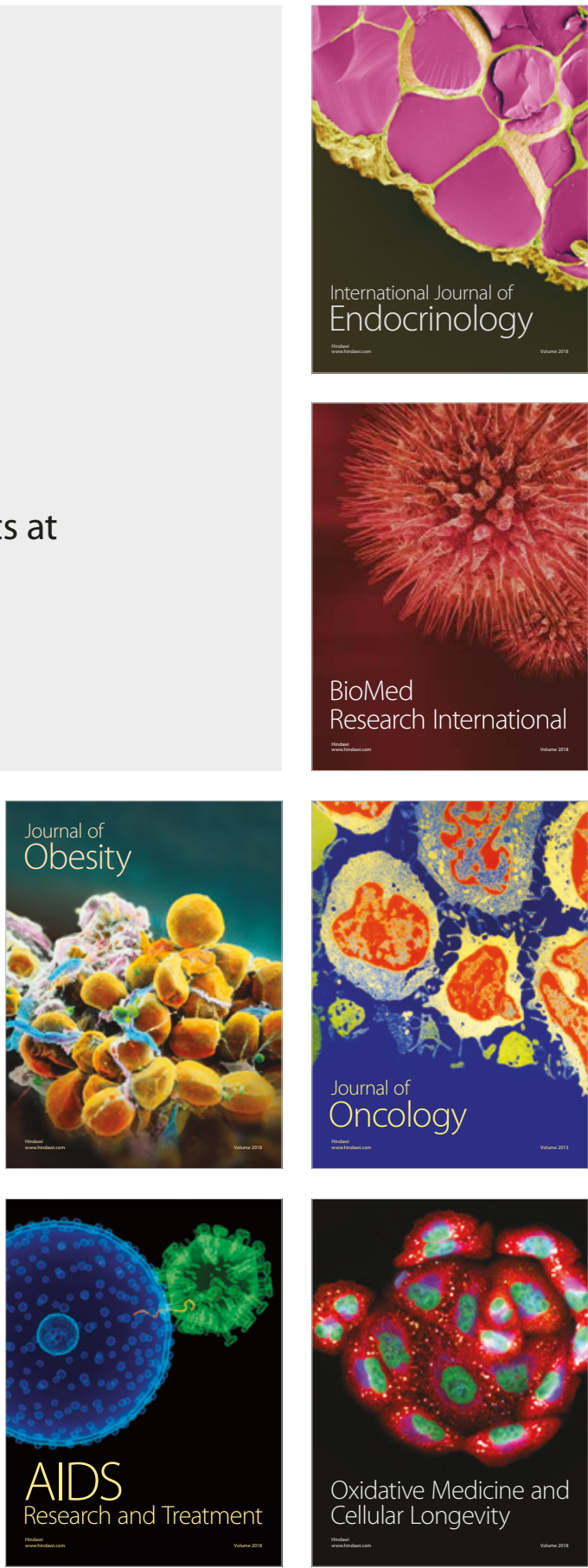